\title{
Antibiotic Use: Knowledge and Practice of Medical Undergraduate Students in Kolkata
}

\author{
Maumita De, ${ }^{1}$ Diptanshu Mukherjee ${ }^{2}$
}

\section{$\underline{\text { Introduction }}$}

\section{$\underline{\text { ABSTRACT }}$}

Excessive use and misuse of antibiotics worldwide, both in human medicine and in agriculture has led to increased occurrence of bacterial resistance. Medical students should be aware of the judicious use of antibiotics, so that they can help the general population in future. Present study assesses knowledge of antibiotic use among first year undergraduate medical students and their practice in own life.

\section{Materials and Methods}

An observational, cross sectional study was conducted during a three-month period among first year undergraduate medical students of a teaching hospital in Kolkata. A validated self- administered questionnaire was used to collect the data. The data were analyzed by using simple descriptive statistics. Wherever it was relevant, the Chi-square test was carried out to determine any significant difference.

\section{Results}

About $85 \%$ of the participants were aware of the indication of antibiotic for treating bacterial infections only. Around $44 \%$ of the students had an average knowledge score compared to 28\% having good knowledge score. Majority (76\%) of the medical students obtained last antibiotics by a doctor's prescription, but $54 \%$ completed the course as advised by doctor and purpose of taking antibiotic was fever mainly (41\%). Statistically significant $(P<0.05)$ difference on pattern of their antibiotic use was found according to their socioeconomic status and knowledge score.

\section{Conclusion}

Changing the prescribing behaviour and knowledge of the healthcare professionals can help a lot to achieve rational use of antibiotic. It is also suggested that giving a comprehensive training of antibiotic use to the medical students and creating their awareness about frequent antimicrobial resistance could be a successful and encouraging approach.

\section{$\underline{\text { Kevwords }}$}

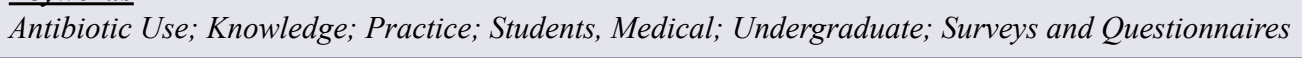

$\mathrm{D}$ iscovery of antibiotics is one of the major events in the history of medicine. Antibiotics are organic substances produced by micro-organisms and capable (at low concentration) of inhibiting the growth of or destroying bacteria. Antibiotic use in both preventive and curative therapy have saved life of countless patients, including those who are receiving chemotherapy, who have chronic diseases such as diabetes, end-stage renal disease or rheumatoid arthritis, who have had complex surgeries such as organ transplants, joint replacements or cardiac surgery and improved patient care in general. ${ }^{1}$

Antibiotic use is widespread. A multi-country public awareness survey by World Health Organization in 2015 reported that $65 \%$ of respondents across the 12 countries had taken antibiotics in the past six months, including more than one third (35\%) who took antibiotics within the past month. Reported antibiotic use is higher (42\%) in the lower income countries included in the survey, compared to higher income countries $(29 \%){ }^{2}$

However, effectiveness of antibiotics is seriously endangered by the emergence of resistant

1 - Department of Community Medicine, NRS Medical

College, Kolkata

2 - Department of ENT, Medical College, Kolkata

\section{Corresponding author:}

Dr Diptanshu Mukherjee

email: diptanshumukherjee@gmail.com 
microorganisms. ${ }^{3}$ The inappropriate use of antibiotics could result from a complex interaction among various factors: prescriber behaviors and knowledge, diagnostic uncertainty, patient demand, free unchecked over the counter (OTC) availability of antibiotics for human, animal and industrial consumption and macro level factors such as sociocultural, economic, and health care regulatory policy. ${ }^{4}$ From patient's perspective, improper antibiotics use such as skipping of doses, reuse of leftover medicines, failure to complete treatment and self-medication with antibiotics have been reported. ${ }^{3}$

Every country and continent is facing the threat of antibiotic resistant "super bugs," though the extent and the severity of the problem varies. ${ }^{5}$ For instance, study conducted among university students in Karachi reported $47.6 \%$ use of antibiotics without doctors' prescription six months prior to study. ${ }^{6}$ Furthermore, about $40 \%$ of Chinese University students used antibiotics without prescription. ${ }^{7}$ India being the country with high infectious disease burden, antibiotics are the most widely and frequently prescribed drugs accounting for the alarming increase in Antimicrobial Resistance (AMR). ${ }^{8}$ A study conducted among students of Mumbai University, India revealed that, $68 \%$ and $79 \%$ participants believed that antibiotics should always be prescribed to treat flu like symptoms and pneumonia. ${ }^{5}$

At present, relatively little is known about the general public's knowledge of antibiotic usage at a global level. First year undergraduate medical students are representing general public without any education regarding antibiotic use. According to World Health Organization, education of healthcare workers and medical students on rational antimicrobial prescribing is an integral part of all antimicrobial resistance containment activities. ${ }^{9,10}$ Unlike many other drugs whose use is generally limited to well-trained specialists (e.g., antipsychotics or chemotherapeutic agents), antimicrobials are prescribed by virtually all doctors and allied healthcare practitioners, regardless of training or knowledge. ${ }^{11-13}$ Therefore, any lacunae in proper education and training about antibiotic use during undergraduate medical period will have high impact on these future prescribers. Hence the present study was undertaken to assess the knowledge and pattern of antibiotic usage in own life of first year undergraduate medical students and also to determine the relationship between antibiotic related behaviour with sociodemographic profile and knowledge score.

\section{Materials and Methods}

\section{Participants:}

An observational, descriptive, cross sectional study was undertaken during a three-month period (from January to March 2019) among first year undergraduate students of NRS Medical College Kolkata, India, who were present on the day of data collection in a lecture theatre of same institution and willing to participate in the study. The purpose of the study was explained to them and they were asked to fill up the pre-designed, pre-tested, semi-structured, paper-based questionnaire within half an hour. Prior Institutional ethics clearance and informed verbal consent were obtained from the participants who were assured of anonymity and confidentiality of information collected. They were asked to communicate if they faced any difficulty in understanding the questions. Those who did not complete the full questionnaire within the stipulated time were excluded from the study.

\section{Questionnaire:}

The self- administered questionnaire was prepared in English and given to four faculty members of Department of Community Medicine to check for content validity. It comprised of three main parts. First part i.e. sociodemographic profile of the study population included data on age, gender, residence, socioeconomic (S.E) status (according to Modified B.G. Prasad's scale classification of 2019)14, father's occupation, mother's occupation, relative in health related field. Second part contained knowledge of medical students about indication of antibiotics and other eight constructs on how and when to take antibiotics. (Table I)

Based on these eight constructs, knowledge score on antibiotic usage was calculated. For each correct response 1 mark was allotted and for wrong response 0 mark. Total score was 8 . It has been arbitrarily classified as good (score 7-8), average (score 4-6), poor (score $\leq$ 3 ). Third part of the questionnaire incorporated pattern 
Table I: Second part of the questionnaire

\begin{tabular}{|c|c|c|}
\hline \multirow{2}{*}{ CONSTRUCTS } & \multicolumn{2}{|c|}{ RESPONSE } \\
\hline & YES & NO \\
\hline a. Do you take antibiotic only with prescription from doctor & & \\
\hline b. Do you complete the full course of antibiotic prescribed by the physician & & \\
\hline c. Do you take antibiotics to prevent any disease (prophylactically) & & \\
\hline d. Is it necessary to take antibiotics for common cold, flu (viral infections) & & \\
\hline $\begin{array}{l}\text { e. Do you save the remaining, leftover antibiotic for the next time when you get } \\
\text { sick }\end{array}$ & & \\
\hline f. Do you return to the physician after the antibiotic treatment & & \\
\hline $\begin{array}{l}\text { g. Do you use antibiotics that were given to a friend or family member, as long as } \\
\text { they were used to treat the same illness }\end{array}$ & & \\
\hline $\begin{array}{l}\text { h. Do you buy the same antibiotics as they helped you get better, when you had } \\
\text { the same symptoms before }\end{array}$ & & \\
\hline
\end{tabular}

of their own antibiotic usage, e.g., time since they took last antibiotic, way of obtaining it, compliance to last antibiotic course as advised by doctor, reason for noncompliance and purpose of taking last antibiotic.

\section{Statistical analysis:}

Collected data were analysed using IBM Statistical Package for Social Science version 20 (SPSS, Inc., Chicago, IL, USA). Descriptive statistics were performed and expressed as proportions (\%). Chi-square test and Fisher's Exact test were carried out to determine the relationship between antibiotic usage behavior with socio-demographic profile and knowledge score. P value of $<0.05$ was considered statistically significant.

\section{Results}

A total of 162 students were present on the day of interview and willing to participate in the study, but 11 of them were excluded from the study due to non completion of key variables of the questionnaire. Thus a total of 151 students were included in the study for final analysis.

\section{A. Socio-Demographic Characteristics:}

It was seen that most of the study population were in the age group of $18-19$ years $(73.5 \%)$, resided in urban area (55\%) and belonged to socio-economic class I (68.9\%) according to modified B.G. Prasad's scale classification of 2019. Male and female participants were almost equal $(51 \% \& 49 \%)$ in the study. Fathers of most of the medical students $(51.6 \%)$ were service holders, while their mothers were mostly $(76.8 \%)$ homemakers. Relatives of most of the study population (58.3\%) were not engaged in health-related field. (Table II)

\section{B.Knowledge on antibiotic usage :}

About $84.8 \%$ of the first year medical undergraduate students agreed that antibiotics were effective for treating bacterial infections only. (Fig. 1)

Knowledge score of study participants was calculated based on eight questions in the questionnaire as described in methodology section. Median knowledge score was found to be 5 and mean knowledge score as $4.86+1.84$ S.D. It was seen that maximum percentage $(43.7 \%)$ of the study population had an average knowledge score compared to $27.8 \%$ having good knowledge score. (Fig. 2) 
Table II: Sociodemographic profile of the study population $(n=151)$

\begin{tabular}{|c|c|c|}
\hline VARIABLES & CHARACTERS & NO (\%) \\
\hline \multirow{3}{*}{ Age Group (years) } & 17 & $3(2.0)$ \\
\hline & 18-19 & $111(73.5)$ \\
\hline & 20-22 & $37(24.5)$ \\
\hline \multirow{2}{*}{ Gender } & Male & 77 (50.9) \\
\hline & Female & 74 (49.1) \\
\hline \multirow{2}{*}{ Residence } & Rural & $68(45.1)$ \\
\hline & Urban & 83 (54.9) \\
\hline \multirow{5}{*}{ Socio-economic class } & I & $104(68.9)$ \\
\hline & II & $13(8.6)$ \\
\hline & III & $11(7.3)$ \\
\hline & IV & $13(8.6)$ \\
\hline & $\mathbf{V}$ & $10(6.6)$ \\
\hline \multirow{5}{*}{ Father's occupation } & Farmer & 18 (11.9) \\
\hline & Business & $26(17.2)$ \\
\hline & Health sector & $11(7.2)$ \\
\hline & Service & 78 (51.6) \\
\hline & $\begin{array}{c}\text { Others (tailor, electrician, driver, } \\
\text { mason etc.) }\end{array}$ & 18 (11.9) \\
\hline \multirow{3}{*}{ Mother's occupation } & Homemaker & $116(76.8)$ \\
\hline & Health sector & $5(3.3)$ \\
\hline & Service & 30 (19.9) \\
\hline \multirow{2}{*}{ Relatives working in health related field } & Yes & 63 (41.7) \\
\hline & No & $88(58.3)$ \\
\hline
\end{tabular}

\section{Pattern of antibiotic usage:}

The study revealed that almost three fourth (73.5\%) of the study population took antibiotics within last 6 months, while 4 out of 151 students had never taken antibiotic before. Majority of the medical students obtained last antibiotics by a doctor's prescription (75.5\%), but $54 \%$ completed the course as advised by doctor. Non compliance about full course of last antibiotics was mainly ( $71 \%$ cases) due to feeling better. About $41 \%$ of participants took last antibiotics for fever. (Table III)

\section{Determinants of antibiotic use behaviour:}

First year undergraduate students had different antibiotic use behaviours depending on their socio-demographic profile and knowledge score. $76 \%$ female participants obtained last antibiotic from doctor's prescription followed by $11 \%$ from medical shop, $8 \%$ from family member, $3 \%$ from other health professional and 1.4\% through online purchase compared to male participants who received last antibiotics from same sources in $71 \%$, $12 \%, 5 \%, 7 \%$ and $1.3 \%$ respectively. The distribution 


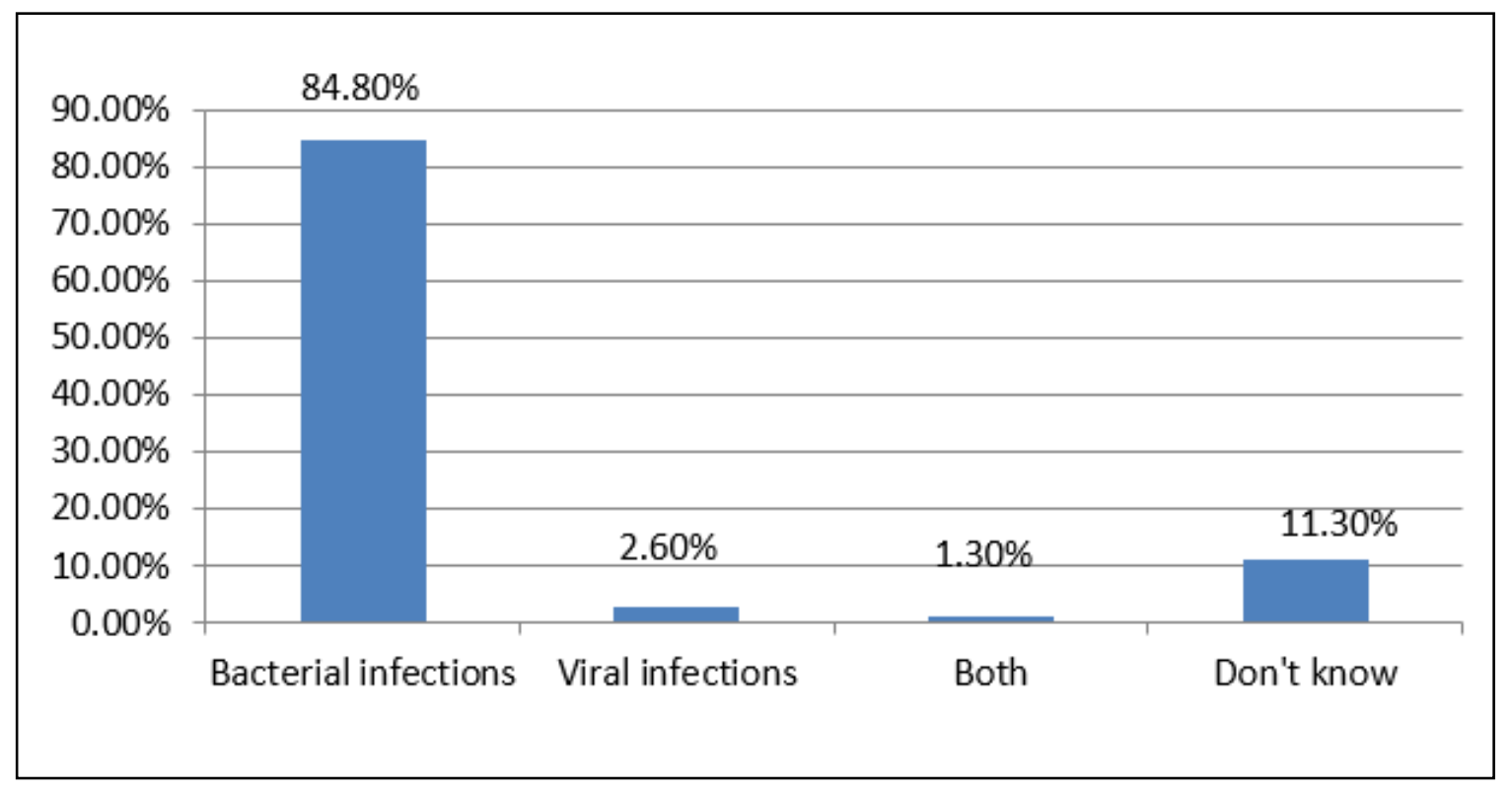

Fig. 1. Graphical representation of age wise distribution of lesions quite nicely depicts the increase in malignancy with increase in age, while the benign section comes down with age was not statistically significant $(\mathrm{P}=0.747)$.Similarly there was no statistical significant difference found in antibiotic use behaviours among rural and urban students $(\mathrm{P}=0.352)$ and also in case of relatives of the students working in health related field or not $(\mathrm{P}=0.629) .80 \%$ of medical students belonging to $\mathrm{S}$.E. class $\mathrm{V}$ took last antibiotics according to doctor's prescription followed by $76.9 \%$ from S.E. class IV, 73\% S.E. class I, 72.7\% from S.E. class III and $69.2 \%$ from S.E. class II and

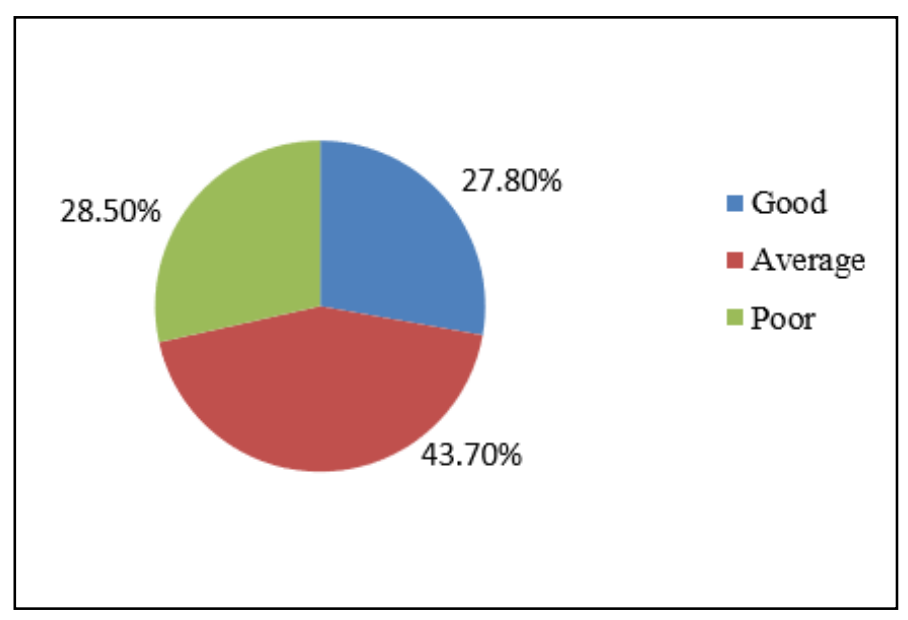

Fig. 2. Pie diagram showing distribution of study population based on their knowledge score of antibiotic usage $(n=151)$ this distribution was found to be statistically significant $(\mathrm{P}=0.031)$. There was a decreasing trend seen in use of last antibiotics as per doctor's prescription, when the knowledge score reduced from good to average to poor (95\%, 74\% and 51\% respectively) and the trend was statistically significant $(\mathrm{P}=0.007)$ (Table IV)

\section{Discussion}

Antimicrobial-resistant organisms are spreading worldwide like wildfire and the main driving factor is irrational use of antibiotics. The future generation doctors must take care of antimicrobial use more responsibly. A cross-sectional study was conducted among first year undergraduate medical students of a NRS Medical College, Kolkata to evaluate their knowledge and pattern of antibiotic usage and to find out the determining factors related to their antibiotic use behaviours.

In the present study most of the students were in the age group of 18-19 years, resided in urban area and belonged to S.E. class I. Male and female participants were almost equal; their fathers were mainly service holders, while their mothers were homemakers predominantly and most did not have any relatives 
Table III: Distribution of study population according to their pattern of antibiotic usage

\begin{tabular}{|c|c|c|}
\hline VARIABLES & CHARACTERS & NO (\%) \\
\hline \multirow{5}{*}{$\begin{array}{l}\text { Time since they took last } \\
\text { antibiotic }(n=151)\end{array}$} & Less than 1 month & $56(37.1)$ \\
\hline & 1- 6 months & $55(36.4)$ \\
\hline & 6 months - 1year & $20(13.2)$ \\
\hline & More than a year & $16(10.7)$ \\
\hline & Never & $4(2.6)$ \\
\hline \multirow{5}{*}{$\begin{array}{l}\text { Way of obtaining last antibiotic } \\
\qquad(\mathrm{n}=147) *\end{array}$} & Doctor's prescription & $111(75.5)$ \\
\hline & Friend or family member & $10(6.8)$ \\
\hline & Medical shop & 17 (11.6) \\
\hline & Online purchase & $2(1.3)$ \\
\hline & Other health professional & $7(4.8)$ \\
\hline \multirow{2}{*}{$\begin{array}{c}\text { Compliance to last antibiotic } \\
\text { course(as advised by doctor) (n } \\
=147) *\end{array}$} & Yes & 79 (53.7) \\
\hline & No & $68(46.3)$ \\
\hline \multirow{3}{*}{$\begin{array}{l}\text { Reasons for non compliance }(n= \\
68)\end{array}$} & After feeling better & $48(70.6)$ \\
\hline & $\begin{array}{l}\text { Others (switched to homeopathy, worsening of } \\
\text { disease condition) }\end{array}$ & $3(4.4)$ \\
\hline & Can't remember & $17(25.0)$ \\
\hline \multirow{5}{*}{$\begin{array}{l}\text { Purpose of taking last antibiotic } \\
\qquad(n=147) *\end{array}$} & Fever & $60(40.8)$ \\
\hline & Cough \& cold & $31(21.1)$ \\
\hline & Diarrhoea & $7(4.8)$ \\
\hline & $\begin{array}{c}\text { Others (postoperative, trauma, eye or ear or throat } \\
\text { infection etc.) }\end{array}$ & $35(23.8)$ \\
\hline & Can't remember & $14(9.5)$ \\
\hline
\end{tabular}

* 4 out of 151 students did not take antibiotic before.

engaged in health-related field.

In this study $84.8 \%$ of the study population agreed that antibiotics were effective for treating bacterial infections only. Similar findings were reported by different studies in India and abroad: 84\% of medical students in Puducherry, ${ }^{15} 90 \%$ of dental \& nursing students from $\mathrm{Nepal}^{16}$ and $92 \%$ of Chinese medical students ${ }^{17}$ believed the same. It was seen that maximum percentage $(43.7 \%)$ of the first year students had an average knowledge score compared to $27.8 \%$ having good knowledge score. In contrast a study conducted among final-year undergraduate pharmacy students from 5 public universities in Malaysia found most of them $(60 \%)$ had a good knowledge score. ${ }^{18}$ The possible reason being final-year pharmacy students have a relatively good understanding of antibiotic use than first year medical students.

Majority (75.5\%) of the medical students in current 


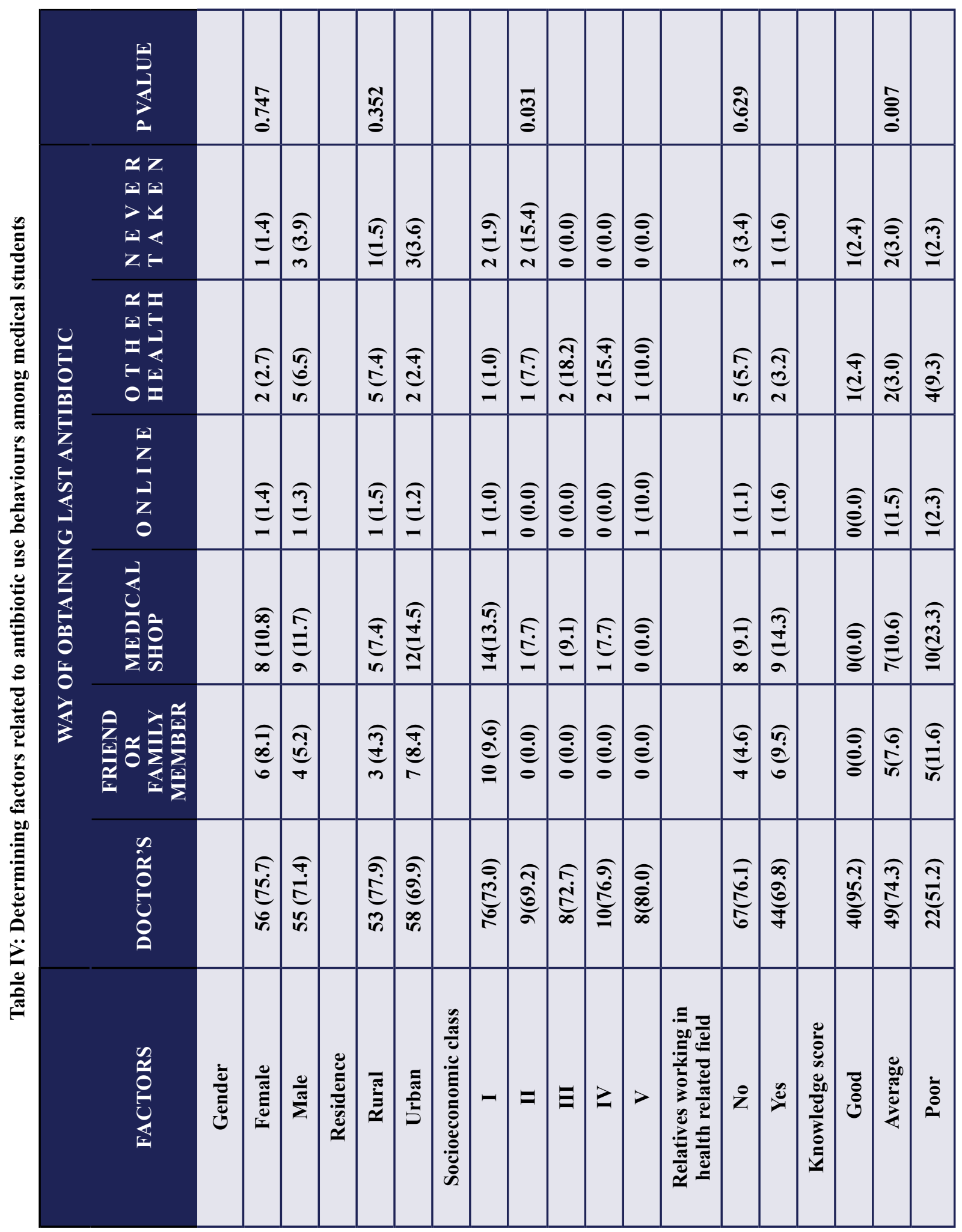


study obtained last antibiotics by a doctor's prescription, but $54 \%$ completed the course as advised by doctor. Likewise in a study majority ( $>70 \%)$ always consulted a doctor before starting an antibiotic and always completed the full course of the prescribed treatment and showed least self-medication practice among medical undergraduates. ${ }^{19}$ While in another study, only $34 \%$ students took antibiotics for various reasons and out of them $27 \%$ completed the entire course. ${ }^{20}$ The present study may have greater risk of recall bias as this study asked about the illness in the past month or the past 12 months or life-time illness, which might overestimate the actual rates of healthcare seeking behavior. Previous study by Kumar et al showed, $46 \%$ of 1 st year and $22 \%$ of 2nd year MBBS students believed that antibiotics need to be prescribed for simple viral illness ${ }^{21}$ and in this study also students practiced the same. Although majority undergraduate students in current study followed doctor's prescription, but unexpectedly the purpose of taking last antibiotic was fever mostly (41\%) followed by cough \& cold $(21 \%)$. It is perhaps not surprising that one of the major reasons that doctors prescribe antibiotic is patient demand, ${ }^{22,23}$ which is likely to be even more common when the patient is a medical student.

While focusing on determinants of antibiotic use behavior among first year medical students, it was found that, it significantly $(\mathrm{P}<0.05)$ varied according to socioeconomic class and knowledge score. However, students' practice of obtaining last antibiotic did not differ significantly by gender, residence and their relatives working in health related field. On the contrary $\mathrm{Hu}$ et al showed that medical students of China, whose fathers had a higher education level, whose mothers had medical background, who were from urban areas and having high KAP scores were significantly more prone to self-medicate with antibiotics. ${ }^{17}$ A probable explanation of the high rate of seeking doctor's advice among the students belonging to S.E. class I could be their affordability and upbringing in an environment of higher education level. Inevitably good knowledge score of participants reflects their better practice of antibiotic use. In several medical schools like Johns Hopkins, Brown University and other U.S universities, antibiotic stewardship program is a compulsory course in current infectious disease fellowship training tenure. ${ }^{24}$ Such programmes could be customized for use in developing countries like India.

\section{Limitations:}

This was a cross-sectional study conducted in a single Institution, thus it is difficult to ascribe causal associations. Self-administered questionnaire can lead to recall bias. A lecture theatre was chosen as a place of study, therefore conversation between students might not be avoided. But the questionnaire answers were completed within half an hour, there was little time for the students to discuss and would only affect knowledge but not own practice.

\section{Conclusion}

Medical students should be taught specifically the judicious use of antibiotic. They should strengthen their communication skills with patients and how to negotiate requests from patients for antibiotics. Medical practitioners are sometimes uncertain how to distinguish between a self-limiting viral illness and a severe bacterial infection; so they need the knowledge and confidence to treat each appropriately without prescribing unnecessary antibiotics. Unsupervised over the counter purchases of antibiotics can be reduced only through changing beliefs and behaviour of patients, doctors as well as pharmacists. National education programs are urgently required to enhance public awareness about rational antibiotic use and it should be incorporated in medical education and outpatient settings to diminish redundant use of antibiotics.

\section{References}

1. Piddock LJV. The crisis of no new antibiotics - what is the way forward? The Lancet Infectious Diseases 2012; 12(3): 249-53

2. Antibiotic Resistance: Multi-country Public Awareness Survey. Geneva, Switzerland: WHO;2015. Available from: http://www. who.int/about/licensing/copyright_form/en/index.html [Last accessed on 2019 July 15]

3. Spellberg B, Bartlett JG, Gilbert DN. The future of antibiotics and resistance. The New England J Med. 2013; 368(4): 299302 
4. Franco BE, Mart'inez MA, S'anchezRodr'iguez MA, Wertheimer AI. The determinants of the antibiotic resistance process. Infection and Drug Resistance 2009; 2(1): 1-11

5. Gard R. Tackling Antimicrobial Resistance: Optimizing Use of an Older Antibiotic-Amoxicillin. Indian J of Cli Pract. 2014; 24(9): $843-5$

6. Shah SJ, Ahmad H, Rehan RB et al. Self-medication with antibiotics among non-medical university students of Karachi: A cross-sectional study. BMC Pharmacology \& Toxicology 2014; $15: 74$

7. Lv B, Zhou Z, Xu G et al. Knowledge, attitudes and practices concerning self-medication with antibiotics among university students in Western China. Tropical Medicine \& International Health 2014; 19 (7): 769-79

8. Prevention and containment of antimicrobial resistance. World health organization. Available at http://www.ino.searo.who. int/LinkFiles/Other_Content_WHD11-Seminar_PresentationWRpdf. [Last accessed 2019 July 15]

9. The evolving threat of antimicrobial resistance. Options for action. World Health Organization. Available at: http://www. who.int/patientsafety/ implementation/amr/publication/en/ index.html. [Last accessed on 2019 July 15]

10. Vickers H. International antibiotic resistance crisis. Better training needed to maintain therapeutic arsenal. Student BMJ 2011; 19: 3207

11. Roumie CL, Halasa NB, Edwards KM, Zhu Y et al.. Differences in antibiotic prescribing among physicians, residents, and nonphysician clinicians. Am J Med. 2005; 118: 641-8

12. Running A, Kipp C, Mercer V. Prescriptive patterns of nurse practitioners and physicians. J Am Acad Nurse Pract. 2006; 18: 228-33

13. Edgar T, Boyd SD, Palame MJ. Sustainability for behaviour change in the fight against antibiotic resistance: a social marketing framework. J Antimicrob Chemother. 2009; 63:2307

14. Pandey VK, Aggarwal P, Kakkar R. Modified B. G. Prasad Socio-economic Classification, update - 2019. IJCM 2019; 31(01): 123-5

15. Jayabalan N, Selvaraj N, Ganesan S et al. A questionnaire based survey on knowledge, attitude and behaviour of antibiotic usage and resistance among undergraduates in South Indian teaching hospital. International Journal of Basic \& Clinical Pharmacology 2018 October; 7 (10): 1991-7

16. Nayak S, Rana M, Mayya SS et al. Antibiotics to cure or harm: Concept of antibiotic resistance among health professional students in Nepal. International Journal of Medical Science and Public Health 2016; 5 (12): 2512-7

17. Hu Y, Wang X, Tucker JD et al. Knowledge, Attitude, and Practice with Respect to Antibiotic Use among Chinese Medical Students: A Multicentre Cross-Sectional Study. Int. J. Environ. Res. Public Health 2018; 15: 1-14

18. Rajiaha K, Rena WS, Jamshed SQ. Evaluation of the understanding of antibiotic resistance among Malaysian pharmacy students at public universities: An exploratory study. Journal of Infection and Public Health 2015; 8: 266-73

19. Padmanabha TS, Nandini $T$, Manu $G$ et al. Knowledge, attitude and practices of antibiotic usage among the medical undergraduates of a tertiary care teaching hospital: an observational cross-sectional study. International Journal of Basic \& Clinical Pharmacology 2016; 5 (6): 2432-7

20. Patil SB, Nagaiah BH, Raikar SR, Rao V. Self-medication practices among 2 nd year medical students in a rural medical college of Telangana state. Natl J Physiol Pharm Pharmacol 2018; 8: 5016

21. Bharath Kumar VD, Kalpana L. A comparative study to assess the awareness of antibiotic resistance amongst first and second year medical undergraduate students in a medical college. International Journal of Basic \& Clinical Pharmacology 2018 August; 7 (8): 1567-71

22. Hulscher ME, Van der Meer JW, Grol RP. Antibiotic Use: How to Improve It? Int. J. Med. Microbiol. 2010 Aug; 300 (6): 351-6

23. Pan X, Slater M, Beacco A, Navarro X, Bellido Rivas AI, Swapp D et al. The Responses of Medical General Practitioners to Unreasonable Patient Demand for Antibiotics-A Study of Medical Ethics Using Immersive Virtual Reality. PLoS One 2016 Feb 18; 11(2): e0146837. [CrossRef] [PubMed]

24. Ostrowsky B, Nori P, Munjal I, Garcia MDC, Seo SK Pooling New York City Resources to Educate Fellows About Antimicrobial Stewardship and Infection Prevention and Control. Open Forum Infect. Dis. 2015, 2. 